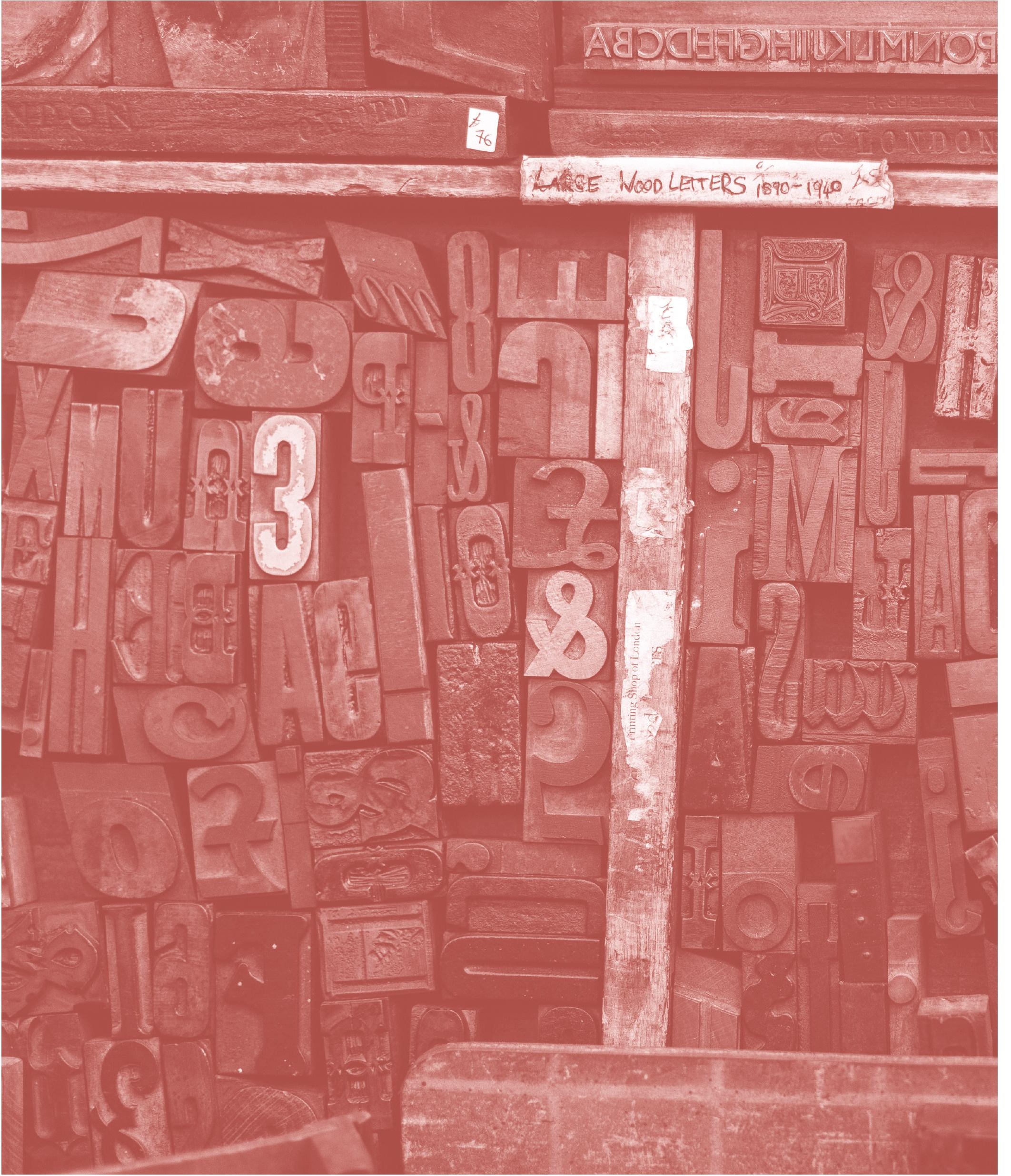




\section{Fuera de contexto Veinte años de editoriales de Periférica Internacional}
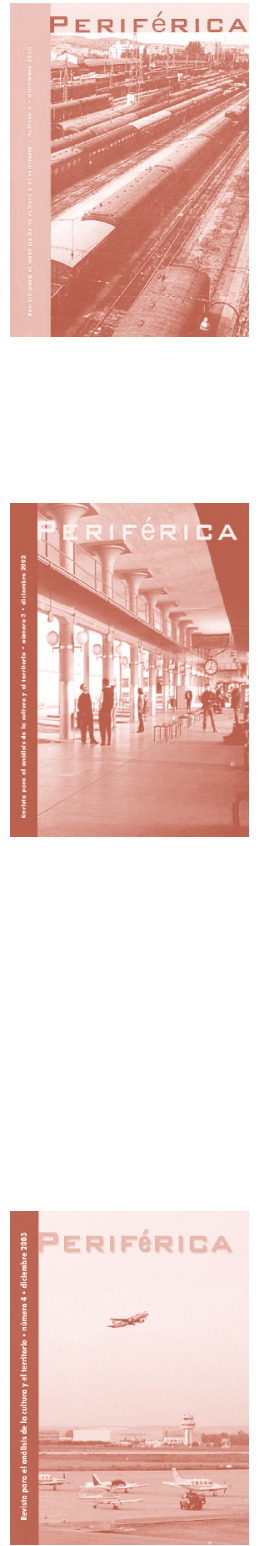

«Periférica es en definitiva el lugar en el que se podrán discutir, razonar y debatir todos estos asuntos. Queremos hablar en serio de cultura y su gestión. Decía Woody Allen que "el arte no imita a la naturaleza. El arte imita a la televisión barata". Y en el mundo actual es muy probable que así suceda. Por todo ello nace Periférica».

Editorial número 1. Año 2000.

«en estos tres años la palabra periférica emerge en casi todos los discursos: en el político. En el territorial, en el social, en el económico y en el artístico. No sabemos si la periferia está de moda. Pero si seguimos echando en falta que la cultura retome el lugar que pensamos le corresponde y esté más presente en los discursos de nuestros políticos, en los intereses de nuestros empresarios, en los objetivos de nuestras asociaciones, en la agenda de nuestros medios de comunicación o en las vidas de nuestros centros educativos».

Editorial número 3. Año 2002.

«expresar nuestra preocupación por el que parece ser el discurso dominante de un tiempo a esta parte en el mundo de la cultura. Aquel que exclusivamente la trata desde la perspectiva de la economía, o más exactamente desde la rentabilidad económica del hecho cultural [...]
Se busca la creación de nuevas centralidades sin pararse a pensar o calibrar las periferias culturales que se generarán [...] Gultura y economía, sí. Pero además cultura y ciudadanía, y valores, y pedagogía, y al mismo tiempo idearios sociales para los equipamientos».

Editorial número 4. Año 2003.

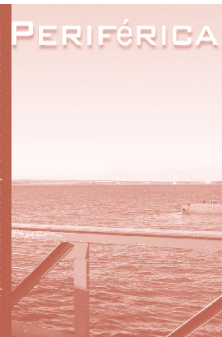

«vemos constantemente una cultura construida sobre la ausencia de contenidos pensados, meditados, compartidos en diálogo entre sus protagonistas [...] la cultura vuelve a ser el papel de celofán para envolver otras cosas consideradas más importantes [...] ¿Dónde están las estrategias que confluyan con la educación de las nuevas generaciones? ¿En qué lugar están las apuestas de riesgo, de innovación? ¿Quién se encarga de la promoción de los creadores? ¿Cuándo iniciaremos proyectos que revitalicen el asociacionismo activo y cívico desde la cultura? [...]

Los responsables políticos están en la obligación de ofrecernos grandes marcos de acción, con contenidos e incluso un poco de ideología si es posible. Los profesionales de la gestión han de esforzarse en construir los instrumentos para la acción cultural desde la coherencia, la honestidad y la eficacia. Los creadores deben explicitar los compromisos tanto con su obra como con la sociedad».

Editorial número 6. Año 2005. 

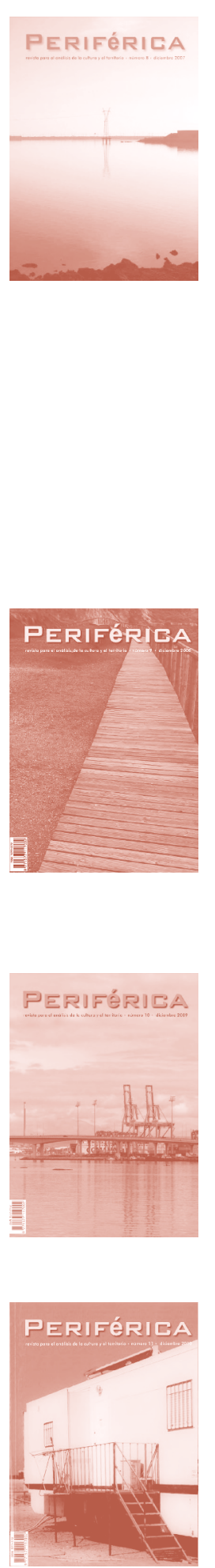

«nuestro públicos, los públicos de la cultura y de las artes están envejeciendo [...] Hasta que las infraestructuras culturales de las ciudades no sean un lugar cotidiano para nuestros niños y jóvenes, hasta que a estos espacios la algarabía retorne, la tarea está completamente por hacer.

Y si los niños y los jóvenes no pasan a ser el centro de nuestros programas y actividades, y si ellos no comienzan a ocupar poco a poco nuestros herméticos templos de la cultura, quizás lo mejor y más sincero es que [...] los borremos, a ellos, de nuestros diccionarios y de nuestras programaciones».

\section{Editorial número 8. Año 2007}

«Un fantasma recorre el mundo global, la crisis económica. Sus efectos se harán sentir y es la hora de la imaginación, la austeridad y la buena gestión. Quienes no se adapten desde estas tres parámetros lo tienen difícil y complicado [...] la crisis es para todos pero no nos iguala. Unos sufren más que otros, pero si es cierto que nos golpeará a todos».

Editorial número 9. Año 2008

«las páginas de la revista (Periférica) se han convertido no solo en un instrumento de comunicación y transmisión de conocimientos y experiencias sino también en testigo y documento de la evolución que la gestión cultural está viviendo en esta última década tanto en la forma como en el fondo».

\section{Editorial número 10. Año 2009}

«asistimos todavía al desinterés o a la sesgada utilización de documentos de referencia emitidos por organismos como la UNESCO o la Unión Europea - Declaración Universal sobre diversidad, Agenda 21 de la Cultura, Convención sobre protección y promoción de la diversidad de las expresiones culturales, Agenda europea de la cultura, Derechos culturales...- que desde diversas perspectivas componen una aportación esencial para la formulación de políticas culturales [...] se constata una empobrecedora corriente de reflexión y la ausencia de un pensamiento capaz de centrar con rigurosidad las cuestiones que la cultura contemporánea propone, así como de articular respuestas a los vertiginosos cambios del sector cultural y a la redefinición de conceptos $[\ldots]$

son los ejes de una estructura precaria que, enlazada con el retroceso de la participación ciudadana y su alejamiento de los procesos de elaboración y control, elimina cualquier actitud crítica, convirtiendo a la ciudadanía en público pasivo cuando no simples consumidores».

Editorial número 11. Año 2010

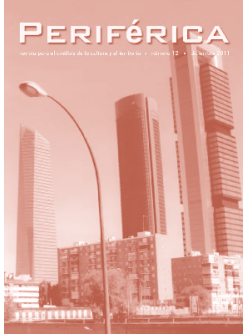

«La cartografía cultural constituye un instrumento de conocimiento que permite comprender tanto el estado cultural de un territorio como un aspecto concreto de un modelo cultural. Por consiguiente, su aplicación resulta idónea y oportuna como estrategia de orientación $[\ldots]$

[la cartografía cultural como] una estrategia que permita impulsar dinámicas y planteamientos aplicados desde perspectivas que reorienten el sistema hacia un cambio de modelo. Un escenario donde se reivindique y reformule la cultura para ser utilizada como necesario paradigma del desarrollo, impregnando con su retórica tanto el discurso político como el social».

Editorial número 12. Año 2011

«Nuestro país, como Andalucía y

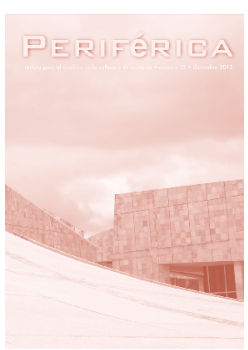
nuestra provincia, ha ensayado y aplicado los diversos modelos de políticas culturales públicas que en el mundo han sido [...] políticas de mecenazgo público [...], programas de becas y formación [...]. Se desparramaron los equipamientos en infraes- 
tructuras culturales por todo el territorio. En este caso, el del ladrillo cultural, hemos llegado a rozar la locura y a fomentar incluso los mayores despropósitos [...] hemos invertido cantidades muy considerables de dinero, pesetas y euros, en proyectos dirigidos al fomento de las industrias culturales [...]. Se nos llenó la boca con la economía de la cultura $[. .$.$] como una moderna cor-$ nucopia para sociedades avanzadas [...], creamos redes de difusión artística para que diseminaran teatro, música, arte, etc. en cada rincón de nuestra nación[...]. No había agenda política [...] que no llevara la palabra cultura en sus programas escrita de firma más o menos ampulosa. Y nos lo creímos. Y se lo creyeron.

La crisis, la que nos está golpeando con dureza y desprecio, nos ha despertado de muchos de nuestros sueños. El despertar ha sido como una pesadilla, el dinosaurio de Monterroso continúa obstinadamente presente en este despertar agrio. Y no tenemos modelo de políticas culturales en la mente, en el alma o en el bolsillo que nos sirva para encararlas.

¿Dónde fallamos? [...] ¿Dónde acertamos?»

Editorial número 13. Año 2012

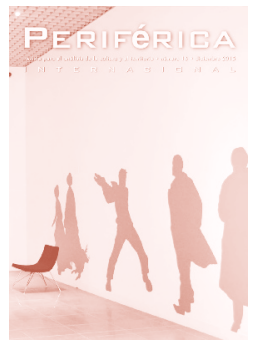

«Que una revista lleve más de quince años saliendo a la calle tiene, como casi todo en la vida, sus ventajas y sus inconvenientes [...].Quince años son casi una vida y por ende en ella hay de todo $[. .$.$] . Nos ha permitido hacer, cono-$ cer y soportar casi de todo en el ámbito que manejamos, en la gestión cultural. Porque la verdad es que el mundo ha cambiado muchísimo, tanto que ya no hay rusos comunistas sino chinos capitalistas, muy capitalistas. Y la cultura, ese objeto polimorfo y de múltiples contenidos, sigue en pos de los cambios del mundo, más líquido que nada en el orbe si creemos al maestro Bauman».

Editorial número 16. Año 2015

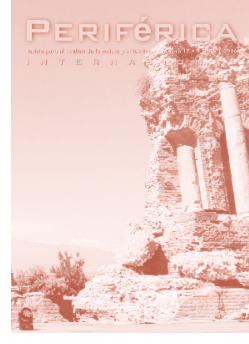

«Estamos en tiempos de cambio, de revisión, quizás sean simplemente tiempos de cuestionamiento [...] existen problemas sin resolver en nuestro sector. En las adminstraciones públicas [...] [en] el sector privado $[\ldots]$

En esta línea quizás, por destacar un problema esencial, la cuestión de los derechos culturales sería una de las prioritarias a abordar. La sociedad del siglo XXI necesita imperativamente definir y concretar los derechos culturales de la ciudadanía. Y ello es esencial porque de esa concreción se deberían derivar los servicios públicos competentes, los ámbitos que correspondan a los mercados de la cultura y su regulación»

Revista número 17. Año 2016

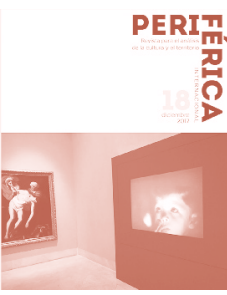

«Muchos cambios en la cabeza
(de la revista Periférica Internacional), las
mismas ganas que hace 18 años y también deseo de oxigenar un Consejo Asesor y un Consejo Científico tremendamente masculino, en el que las canas ya son norma».

\section{Revista número 18. Año 2017}

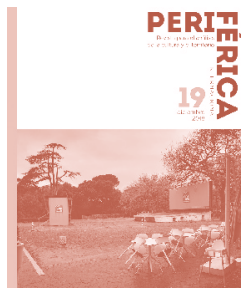

«El 13 de junio del año 2018, los medios de comunicación escrita nos regalaron titulares del tipo "El gestor cultural José Guirao, nuevo ministro de Cultura y Deporte" [...] nos sorprendió el uso, por fin generalizado, del término gestor cultural asociado a todo un señor ministro [...] hemos visto crecer esta profesión, este perfil laboral $[. .$.$] cómo se ha ido abriendo paso$ aquella profesión incipiente que comenzó por los técnicos de cultura y por algunos animadores socioculturales reconvertidos [...] aunque las plagas y amenazas sigan siendo todavía muchas: precarización de los gestores culturales del ámbito privado, gestores públicos envejecidos con escaso relevo generacional o primeras promociones de profesionales surgidos de la universidad en un entorno laboral complejo, entre ellas. 
Uno de los principales retos pasa por ajustar las competencias genéricas y específicas de cualquier gestor cultural al entorno líquido y cambiante que ha venido para quedarse».

Revista número 19. Año 2018

Periférica Internacional. Cádiz, diciembre de 2019 